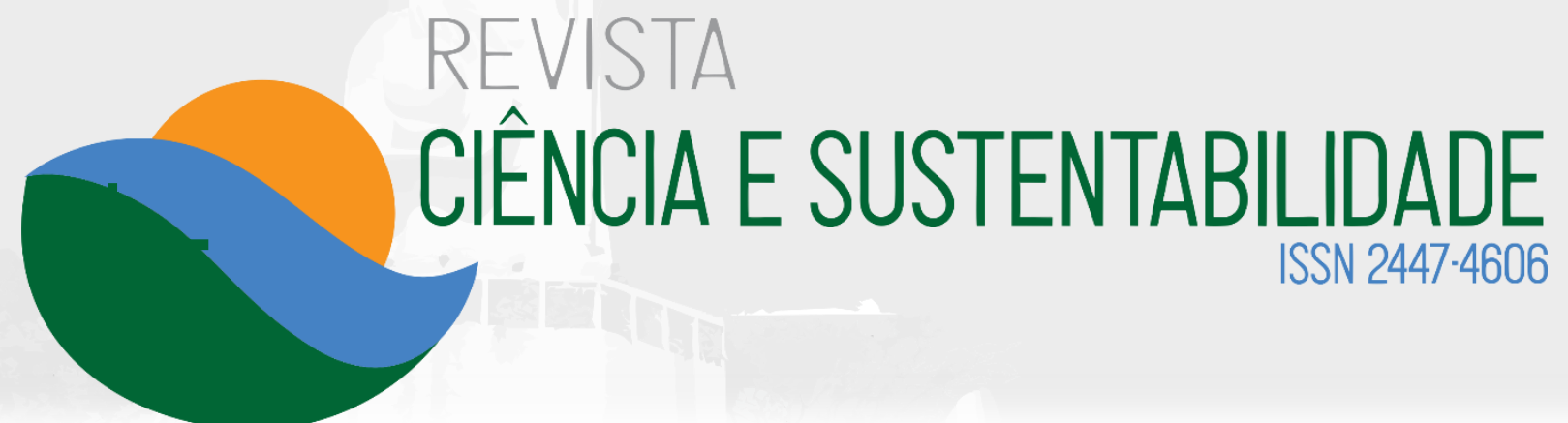

\title{
Classificação, quantificação e ocorrência de eventos climáticos extremos nas três mesorregiões do estado de Alagoas, Brasil
}

\author{
Classification, quantification and occurrence of extreme \\ climate events in the three mesorregions of the state of \\ Alagoas (BR)
}

Maria José da Silva Lima
Universidade Federal de Alagoas, UFAL,
Graduanda em Metereologia pela
Universidade Federal de Alagoas, UFAL,
E-mail: maryah_lima@hotmail.com

lara Bezerra da Silva Cavalcante

Universidade Federal de Alagoas, UFAL, Graduanda em Metereologia pela Universidade Federal de Alagoas, UFAL, E-mail: iaracalv@hotmail.com

\section{Helen da Silva Mendonça}

Universidade Federal de Alagoas, UFAL, Graduanda em Metereologia pela Universidade Federal de Alagoas, UFAL, E-mail: helen-s.mendonca@hotmail.com

\section{Pedro Fernandes de Souza Neto}

Universidade Federal de Alagoas, UFAL, Graduando em Metereologia pela

Universidade Federal de Alagoas, UFAL, E-mail: piufernandes@hotmail.com

\section{Silvania Donato da Silva}

Universidade Federal de Alagoas, UFAL, Graduanda em Metereologia pela Universidade Federal de Alagoas, UFAL, E-mail:

silvaniadonatodasilva@gmail.com

\begin{abstract}
RESUMO
A seca meteorológica é baseada no déficit de precipitação e sua comparação em relação ao valor normal. Visto que seca é um evento complexo, tendo influência local ou regional, e estudá-la é de suma importância para o planejamento e gestão dos recursos hídricos, objetiva-se aplicar e analisar o Índice de precipitação padronizado (SPI) para classificação e quantificação dos eventos extremos secos e chuvosos para o Estado de Alagoas, e identificar anos de maiores déficits e/ou excesso de precipitação. Foram utilizados dados pluviométricos da Agência Nacional das Águas (ANA), no período de 1963 a 2001 para algumas cidades da região Agreste, Sertão e Leste de Alagoas. Para o cálculo do SPI foi utilizado a distribuição gama e estimados os limites de precipitação que representam a cada categoria do índice. Os resultados mostraram que todas as cidades apresentam maiores ocorrências de secas que chuvas, no entanto, para a categoria extrema os eventos de chuva mostraram-se mais frequentes. Já eventos extremos, tanto secos quanto chuvosos, ocorreram em boa parte da série em anos de ENOS, e os anos normais foram os persistentes em todas cidades estudadas. De modo geral, os eventos secos mostram maior percentual de ocorrência, ou seja, existem mais casos secos, porém de baixa intensidade. O SPI revelou-se uma ferramenta útil e eficiente para detecção e monitoramento de seca/chuvas no Estado analisado.
\end{abstract}

Palavras-chave: Secas. ENOS. SPI. 
Classificação, quantificação e ocorrência de eventos climáticos extremos nas três mesorregiões do estado de Alagoas, Brasil

\section{Davi de Oliveira Cavalcante Amorim}

Universidade Federal de Alagoas, UFAL, Graduando em Metereologia pela Universidade Federal de Alagoas, UFAL, E-mail: davi_cavalcante@live.com

\section{Djane Fonseca Da Silva}

Universidade Federal de Alagoas, UFAL, Bacharel em Meteorologia pela Universidade Federal de Alagoas (2003), Mestrado em Meteorologia pela Universidade Federal de Campina Grande (2005) e Doutorado em Recursos Naturais pela Universidade Federal de Campina Grande (2009). Profa. Associado I da Universidade Federal de Alagoas (UFAL), Campus Maceió, no Instituto de Ciências Ambientais - ICAT, curso de Meteorologia, E-mail: djane.silva@icat.ufal.br

Recebido em: 25/10/2018 I Aceito em: $12 / 11 / 2018$

\section{ABSTRACT}

The meteorological drought is based on the precipitation deficit, and its comparison with the normal value. Since drought is a complex event, having local or regional influence and studying it is of paramount importance for the planning and management of water resources, it aims to apply and analyze SPI for classification and quantification of extreme dry and rainy events, for the State of Alagoas, and identify years of major deficits and / or excess precipitation. Rainfall data from the National Water Agency (ANA) were used in the period from 1963 to 2001 for some cities in the Agreste, Sertão and East regions of Alagoas. For the SPI calculation was used the gamma distribution, and the precipitation limits representing each category of the index were estimated. The results showed that all cities present greater drought occurrences than rainfall, but for the extreme category the rainfall events were more frequent. Extreme events, both dry and rainy, occurred in most of the series in years of ENSO, and the normal years were persistent in all cities studied. In general, dry events show a higher percentage of occurrence, that is, there are more dry cases, but of low intensity. SPI has proved to be a useful and efficient tool for the detection and monitoring of drought / rainfall in the analyzed State.

Keywords: Drought. ENSO. SPI. 


\section{INTRODUÇÃO}

A precipitação pluviométrica tem sido o elemento do clima que provoca as transformações mais rápidas na paisagem do meio tropical e subtropical, sobretudo durante o verão, como episódios de chuvas concentradas (chuvas intensas ou aguaceiros), que ocorrem anualmente; não raras vezes resultam em tragédias, principalmente na zona costeira e nas grandes cidades (DA SILVA, 2014).

A seca meteorológica é baseada no déficit de precipitação e sua comparação em relação ao valor normal. Sendo expressa em intensidade e duração do período seco. Configura-se pela falta de água provocada pelo desequilíbrio entre evaporação e precipitação, dependendo também de outros fatores como temperatura, velocidade do vento, umidade do ar e insolação (FERNANDES et al., 2009).

Visto que seca é um evento complexo, tendo influência local ou regional e estudá-la é de suma importância para o planejamento e gestão dos recursos hídricos, meteorologistas e hidrólogos propuseram índices para detectar, caracterizar e monitorar as secas. Em muitas regiões brasileiras, não há definições dos limites de precipitação para classificação da seca ou umidade em determinada região e, portanto, os índices de seca podem permitir a detecção, caracterização e monitoramento do fenômeno. Dentre estes índices tem-se em destaque o Índice de Precipitação Padronizado (SPI) que permite caracterizar o déficit ou o excesso de precipitação em uma determinada localidade ou região (ULIANA, et al., 2015).

Os autores estudaram a utilização do índice de precipitação padronizado para a região norte do estado do Espírito Santo, o SPI mostrou-se um método simples e eficaz para caracterização e monitoramento da seca e da umidade na região norte do estado.

Desenvolvido por Mckee et al. (1993) o índice de seca conhecido por SPI tem com interesse monitorar e analisar a seca em diferentes escalas de tempo. Esse índice é extremamente vantajoso em relação aos demais, visto que utiliza apenas dados mensais de precipitação. Desde que foi proposto, o SPI continua a ser usado em diversos estudos, devido a sua capacidade de quantificar tanto o déficit ou 
excesso de precipitação em diversas escalas temporais, permitindo que regiões com diferentes características climáticas sejam comparadas (MACEDO et al., 2010).

O SPI tem diversas características que são uma melhoria em comparação a outros índices, incluindo sua flexibilidade temporal e simplicidade, que possibilitam sua aplicação para recursos hídricos em todos os prazos (HAYES et al., 1999).

Ao estudar a seca de 1996 nas planícies do Sul e no sudoeste dos Estados Unidos usando o SPI e o Índice de severidade de Seca Palmer (PDSI) Hayes et al. (1999) verificaram que o SPI é uma ferramenta que deve ser aplicada operacionalmente como conjunto de um sistema de observação de seca estadual, regional ou nacional nos Estados Unidos. Segundo os autores, durante a seca de 1996, o SPI detectou o início da seca pelo menos 1 mês antes do PDSI.

Macedo et al. (2010) ao analisar o Índice Padronizado de Precipitação (IPP) para o estado da Paraíba utilizou o IPP nas escalas de tempo de 12 (IPP-12) e 24 (IPP-24) meses, mostraram a ocorrência de secas severas para as três sub-regiões. O IPP-12 mostrou a ocorrência de secas com maior duração entre o período de 1990 a 1994 nas cidades de Araruna e Coremas. Como também, identificou secas extremas na cidade de Monteiro. Já o IPP-24 detectou seca severa, com maior duração em Coremas no período de 1991 a 1995. Essas secas foram intensificadas nesses períodos, possivelmente, devido à ação do El Niño. OS IPP-12 meses e IPP24 meses mostraram bastante eficazes para o monitoramento das secas no Estado. Assim, objetiva-se aplicar e analisar o SPI para quantificação dos eventos extremos secos e chuvosos, de acordo com a frequência entre 1961 a 2014, para o Estado de Alagoas, e identificar anos de maiores déficits e/ou excesso de precipitação.

\section{MATERIAL E MÉTODOS}

\section{1 Área de Estudo}

Alagoas (Figura 1) é um dos 27 Estados que compõe o Brasil, e um dos 9 da região Nordeste, sendo o segundo menor estado do país com uma área de 27.767,661 $\mathrm{km}^{2}$, contendo 102 municípios e uma população estimada de 3.375 .823 pessoas (IBGE, 2017), sua capital é Maceió (latitude: $-9,6^{\circ}$ e longitude: $-35,44^{\circ}$ ). 
Figura 1 - Mesorregiões de Alagoas.

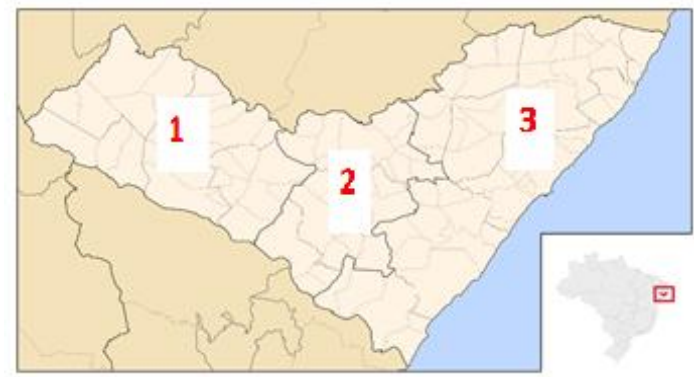

1-Sertão

2-Agreste

3-Leste

Fonte: Suporte Geográfico (2018).

O clima de Alagoas é classificado como Tropical Atlântico, devido sua localização entre os trópicos e próximos ao mar. Na região Leste do Estado, as chuvas são mais regulares, no Sertão, o índice de chuva é baixo, tornando a região seca; o clima de Alagoas pode ser dividido em úmido (Maceió e extremo norte), subúmido (Leste) e semiárido (Centro e Oeste), a amplitude térmica média fica em torno dos $6^{\circ} \mathrm{C}$ com temperaturas entre $21^{\circ} \mathrm{C}$ e $27^{\circ} \mathrm{C}$. Os sistemas meteorológicos que atuam sobre o Estado são: a Zona de Convergência Intertropical (ZCIT), que é responsável pelas chuvas nos meses de março e abril; os Sistemas Frontais (SF), geradores das chuvas frontais que advêm do Atlântico Sul; os Alísios de Sudeste e Nordeste, que provocam chuvas no inverno e pouco avançam em direção ao interior do continente; e as Ondas de Leste (OL), nuvens que se movem no Oceano Atlântico (MOLION e BERNARDO, 2002).

\subsection{Dados}

Foram utilizados dados diários e mensais de precipitação para todas as cidades citadas na Tabela 1, obtidos através da Agência Nacional das Águas (ANA), e com período de 1963 até 2001. Com esses dados foram calculados os SPIs (Índice de Precipitação Padronizado). As cidades utilizadas estão divididas em três 
mesorregiões: Santana do Ipanema, Delmiro Golveia, Batalha, Pão de Açúcar e Piranhas (Sertão); Traipu (Agreste) e Murici, Igreja Nova, Flexeiras, Piaçabuçu (Leste Alagoano ou Zona da Mata). Para classificar os anos como El Niño ou La Niña, foram utilizados os dados do CPTEC (2017) (Figura 2).

Tabela 1 - Localização geográfica das cidades

\begin{tabular}{c|c|c|c} 
Cidade & Região & Longitude & Latitude \\
\hline Santana do Ipanema & Sertão & $-37,95^{\circ}$ & $-9,06^{\circ}$ \\
\hline Delmiro Golveia & Sertão & $-37,93^{\circ}$ & $-9,7^{\circ}$ \\
\hline Batalha & Sertão & $-37,6^{\circ}$ & $-9,33^{\circ}$ \\
\hline Pão de Açúcar & Sertão & $-37,63^{\circ}$ & $-9,63^{\circ}$ \\
\hline Piranhas & Sertão & $-37,15^{\circ}$ & $-9,03^{\circ}$ \\
\hline Traipu & Agreste & $-37,15^{\circ}$ & $-9,2^{\circ}$ \\
\hline Piaçabuçu & Zona da Mata & $-36,5^{\circ}$ & $-10,73^{\circ}$ \\
\hline Igreja Nova & Zona da Mata & $-36,66^{\circ}$ & $-10,12^{\circ}$ \\
\hline Murici & Zona da Mata & $-35,94^{\circ}$ & $-9,30^{\circ}$ \\
\hline Flexeiras & Zona da Mata & $-35,78^{\circ}$ & $-9,19^{\circ}$
\end{tabular}

Fonte: Autores, 2018.

Os gráficos gerados para série temporal do SPI apresentam falhas no momento em que não há dado de precipitação disponível, sendo no caso específico do SPI, não realizando preenchimento da falha para não subestimar nem superestimar o evento. O SPI também não apresenta valor quando seu resultado é zero, significando evento normal, nem seca, nem chuva acima da média. 
Figura 2 - Ocorrência dos eventos de El Niño e La Niña. Fonte CPTEC, 2018.

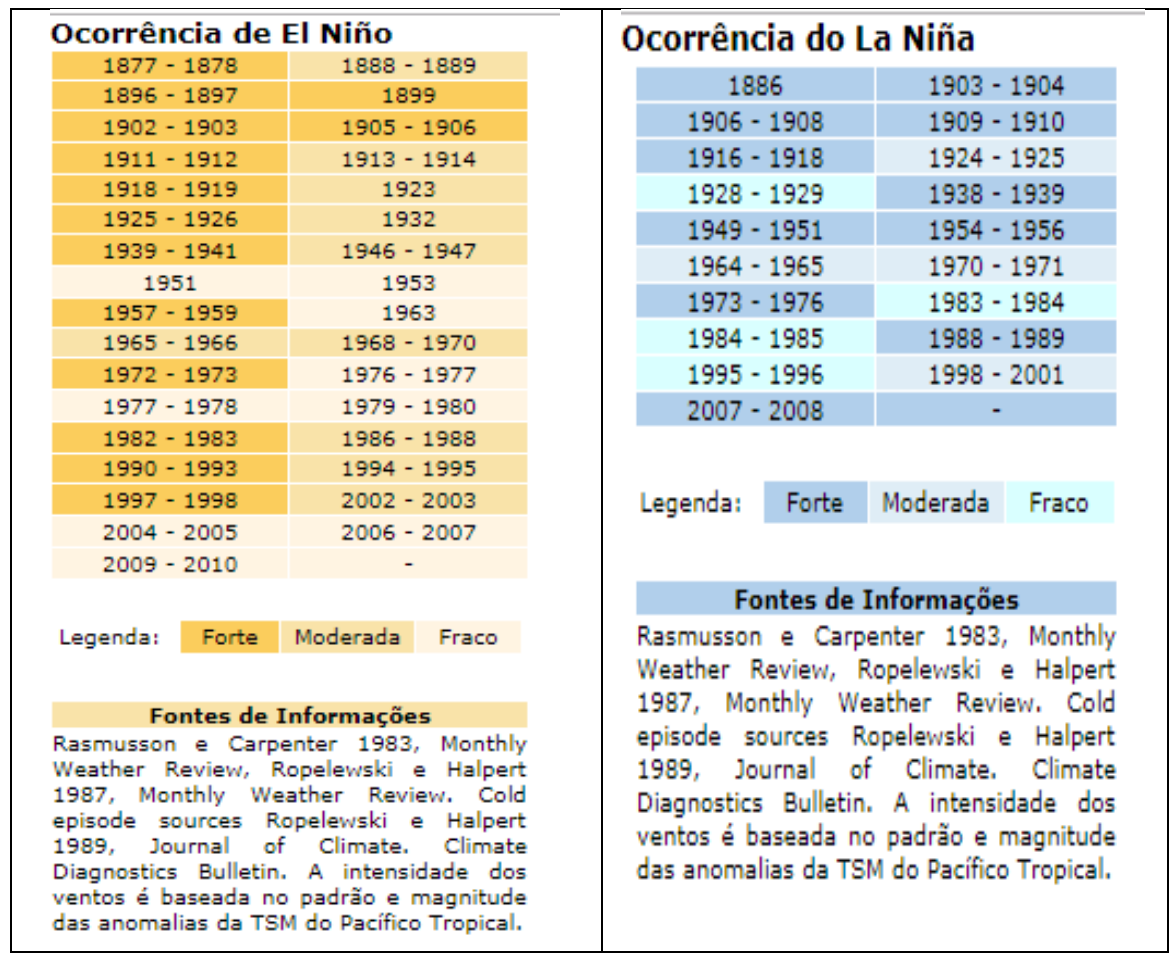

Fonte: Autores, 2018.

\section{3 Índice de Precipitação Normalizada (SPI)}

O cálculo do SPI se inicia determinando uma função de densidade de probabilidade que descreve as séries temporais. A distribuição gama possui bom ajuste para variáveis contínuas que tenham limite inferior ou igual a zero e não possuem limite superior, por isso, é largamente utilizada para o estudo de séries históricas de precipitação (WILKS, 2006 Apud SANTOS et al, 2017).

A função gama é dada por:

$$
g(x)=\frac{X^{\alpha-1} * e^{\frac{-x}{\bar{B}}}}{\beta^{\alpha} \Gamma(\alpha)} \operatorname{para} X>0
$$

, sendo: $a>0$ parâmetro de forma; $\beta>0$ parâmetrode escala; $x>0$, a quantidade de precipitação $(\mathrm{mm})$ e $\Gamma(\mathrm{a})$ a função gama completa. Para estimativa dos parâmetros a e $\beta$ da distribuição gama

utilizou-se o método de

$$
\alpha=\frac{1}{4 A}\left(1+\sqrt{1+\frac{4 A}{3}}\right) \mathrm{e} \hat{\beta}=\frac{\bar{x}}{\alpha},
$$

$A=\ln (\bar{x})-\frac{\Sigma \ln (x)}{n}$,

, Sendo x a precipitação média e , onde o n é número de observações. 
Deste modo que a distribuição cumulativa é então transformada em distribuição probabilidade normal com média igual a zero e desvio padrão igual a um. Em seguida, a probabilidade acumulada de ocorrência de cada valor mensal é estimada. Aplica-se a essa probabilidade a função normal inversa para encontrar o valor do SPI. O SPI nada mais é que a diferença da precipitação observada menos a média do intervalo de tempo específico, dividida pelo desvio padrão, conforme

equação (SANTOS et al, 2017):

$$
S P I=Z_{i}=\frac{\left(P_{i}-\bar{P}_{i}\right)}{\sigma_{i}}
$$

Sua classificação é dada na Tabela 3:

Tabela 2 - Classes e valores de SPI.

Classificação dos períodos secos e chuvosos do SPI

\begin{tabular}{c|c}
\hline Valores de SPI & Classes \\
\hline$<-2,00$ & Seca Extrema \\
\hline$-1,99$ a $-1,50$ & Seca Severa \\
\hline$-1,49$ a $-1,00$ & Seca Moderada \\
\hline$-0,99$ a $-0,49$ & Seca Leve \\
\hline$-0,48$ a 0,48 & Quase normal \\
\hline 0,49 a 0,99 & Chuva Leve \\
\hline 1,00 a 1,49 & Chuva moderada \\
\hline 1,50 a 1,99 & Chuva Severa \\
\hline$>2,00$ & Chuva Extrema
\end{tabular}

Fonte: Adaptado de Santos et. al. (2017).

\section{RESULTADOS}

Classificações de eventos chuvosos e secos extremos através do SPI foram realizadas em vários trabalhos, em diferentes lugares do Brasil: Paraíba (MACEDO et al., 2010); Piauí (GUEDES et al., 2012); Piracicaba-SP (SANGIOLO, 2014); Espírito Santo (ULIANA et al., 2015); Bahia (Sousa et al., 2016); Amazônia (SANTOS et al., 2017); São Paulo (BONFIM \& DA SILVA, 2018); os autores respectivos afirmam que o SPI mostra ser uma importante ferramenta na detecção dos eventos extremos de chuvas/secas. 
Após o cálculo do SPI para a cidade de Batalha (Figuras 3 e 4), foi observado que na maioria dos dados (58\%) os anos foram classificados como foi quase normal, porém $28 \%$ foi de secas e $3 \%$ de seca severa, nos meses de maio até julho, sendo a maior seca em julho de 1963, ano que ocorreu El Niño fraco. A chuva acima do normal foi observada com $14 \%$ de frequência de ocorrência, e a maior chuva extrema foi em julho de 1963.

Figura 3 - Número de casos de chuva/seca em Batalha (Sertão)

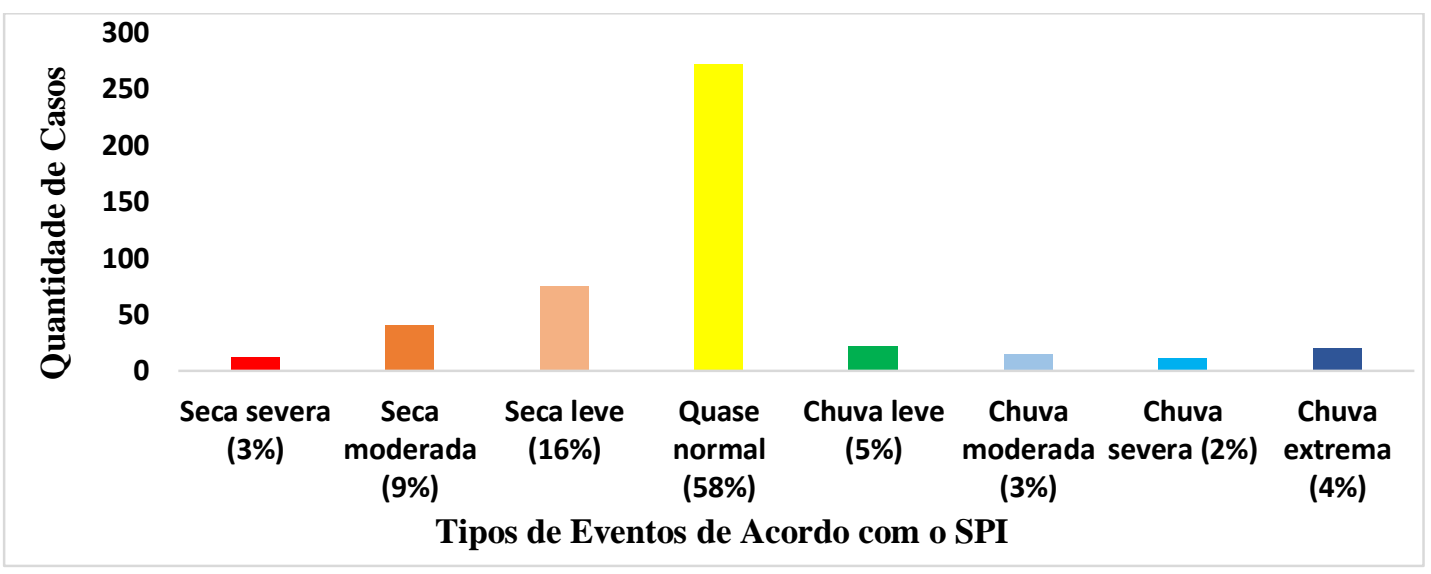

Fonte: Autores (2018).

Figura 4 - Série de SPI para Batalha (Sertão)

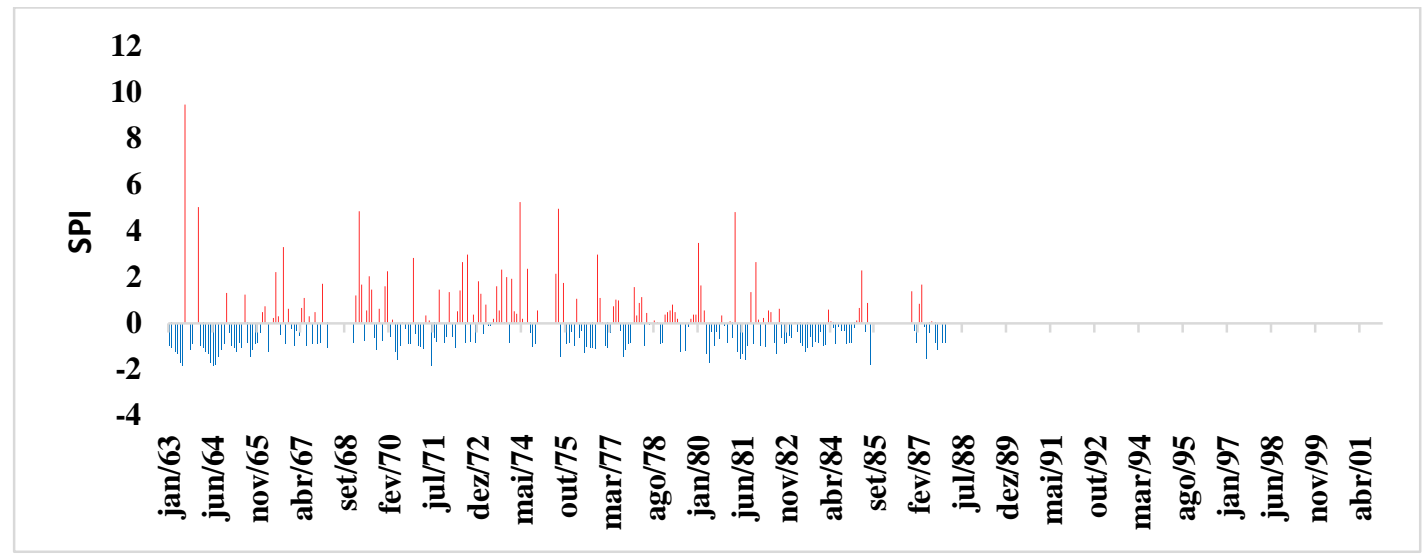

Fonte: Autores (2018).

Em Delmiro Golveia (Figuras 5 e 6) foi registrada $72 \%$ de secas, a seca mais severa foi registrada em junho de 1983, ano que ocorreu um forte El Niño. Ocorreram apenas 10 casos de seca severa, que representa $2 \%$ de todos os casos. A maioria dos casos classificou-se como quase normal, com $58 \%$, já as chuvas foram registradas 
em $15 \%$ dos casos, e as chuvas extremas foram $6 \%$, com a mais forte em abril de 1966.

Já na cidade de Pão de Açúcar (Figuras 7 e 8), 46\% dos eventos enquadrou-se como quase normal. Já a quantidade de secas na cidade foi quantificada em $34 \%$ dos casos, não sendo observada seca extrema, apenas moderada e leve. Os meses de março, maio, junho, julho, agosto e setembro apresentaram as maiores secas, sendo a maior registrada em maio de 1970. Já os eventos de chuva da cidade foram totalizados em $20 \%$, com $5 \%$ de chuva extrema, e o maior volume de chuva registrado em outubro de 1976, ano em que ocorreu uma forte La Niña.

Figura 5 - Número de casos de chuva/seca em Delmiro Golveia (Sertão)

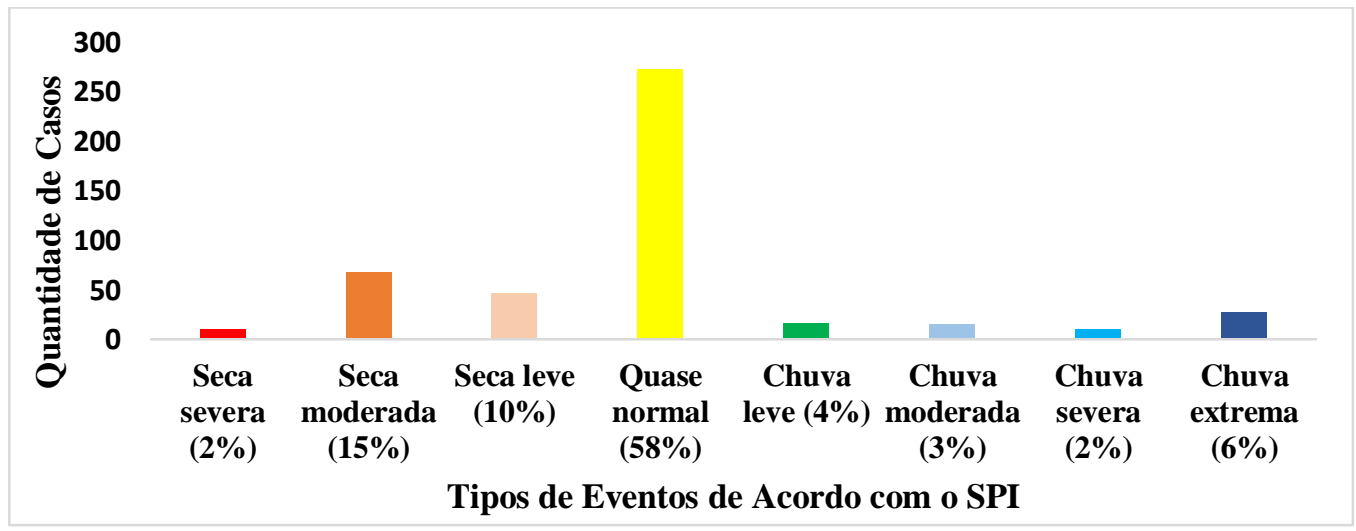

Fonte: Autores (2018).

Figura 6 - Série de SPI para Delmiro Golveia (Sertão)

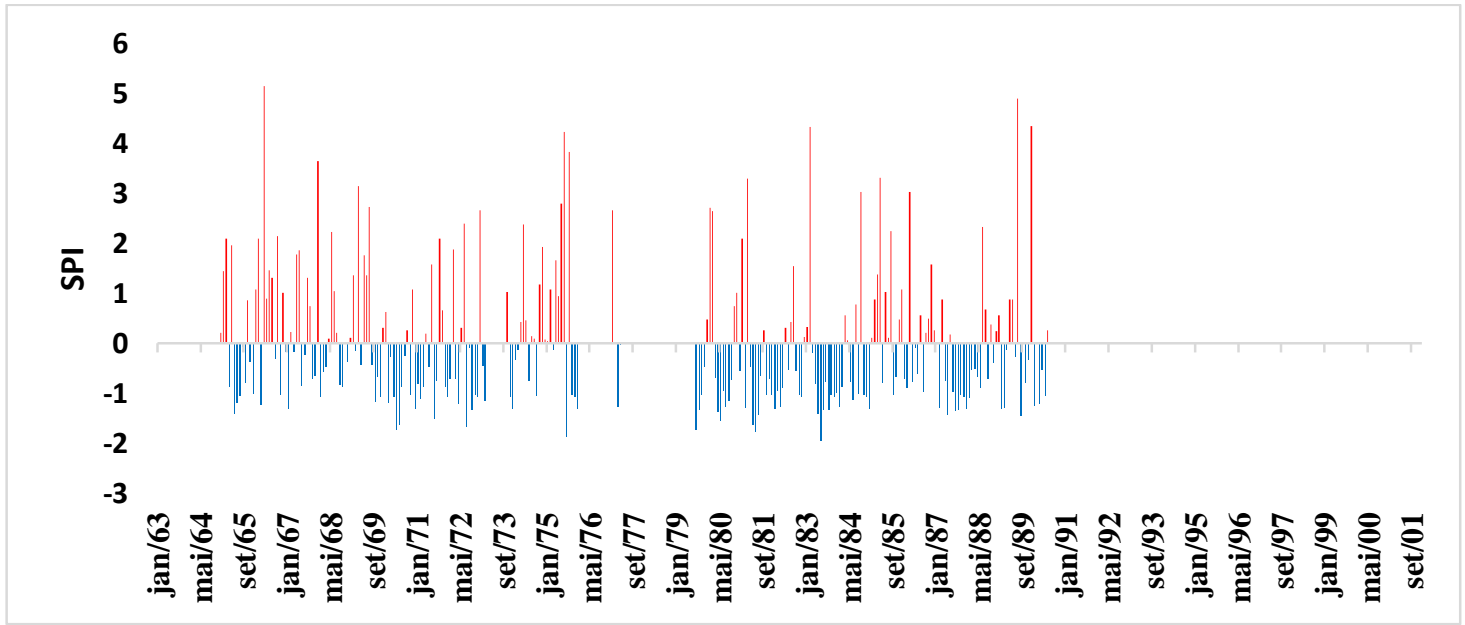

Fonte: Autores (2018). 
Figura 7 - Número de casos de chuva/seca em Pão de Açúcar (Sertão)

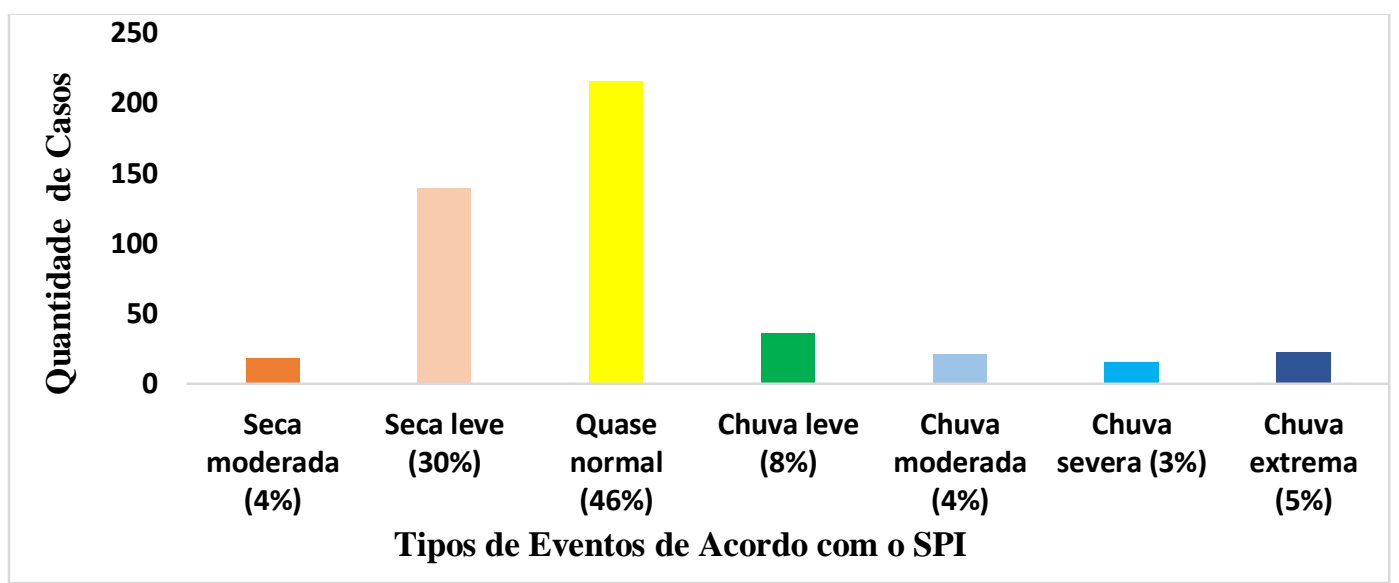

Fonte: Autores (2018).

Figura 8 - Série de SPI para Pão de Açúcar (Sertão)

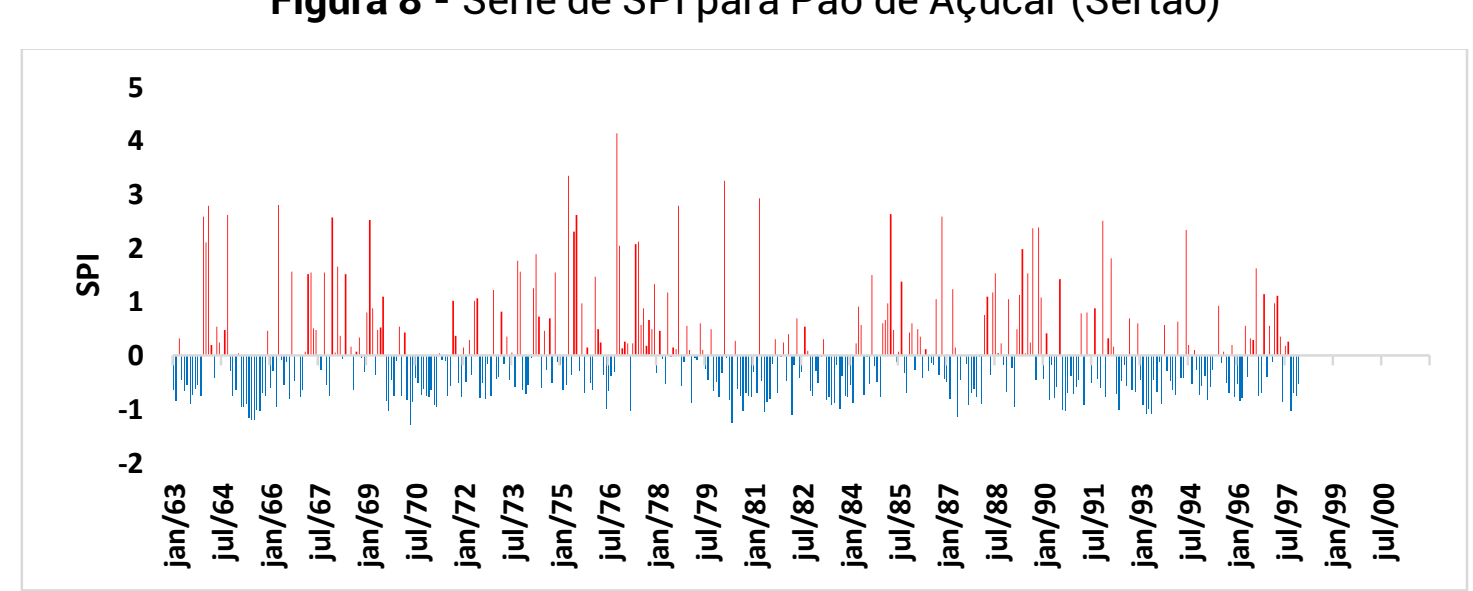

Fonte: Autores (2018).

Já em Piranhas (Figuras 9 e 10), apenas $41 \%$ dos eventos foram quase normais, e $38 \%$ classificados como secas, sendo a maioria das secas registrada como seca leve (30\%), e a seca mais severa tendo ocorrido em Julho de 1991, ano em que teve um forte El niño. Já todas as chuvas acima da média totalizaram 21\% dos casos, e a chuva mais extrema foi em Julho de 1975, ano de forte La niña (CPTEC, 2018). 
Classificação, quantificação e ocorrência de eventos climáticos extremos nas três mesorregiões do estado de Alagoas, Brasil

Figura 9 - Número de casos de chuva/seca em Piranhas (Sertão)

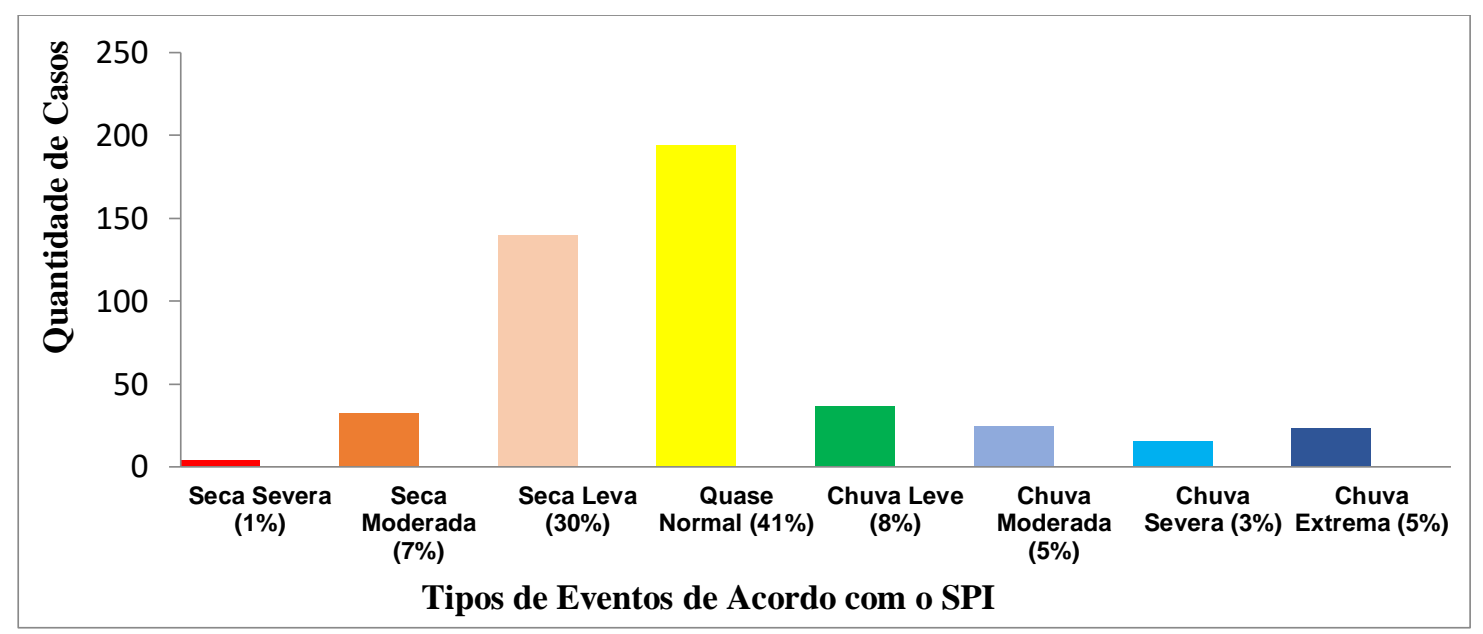

Fonte: Autores (2018).

Figura 10 - Série de SPI para Piranhas (Sertão)

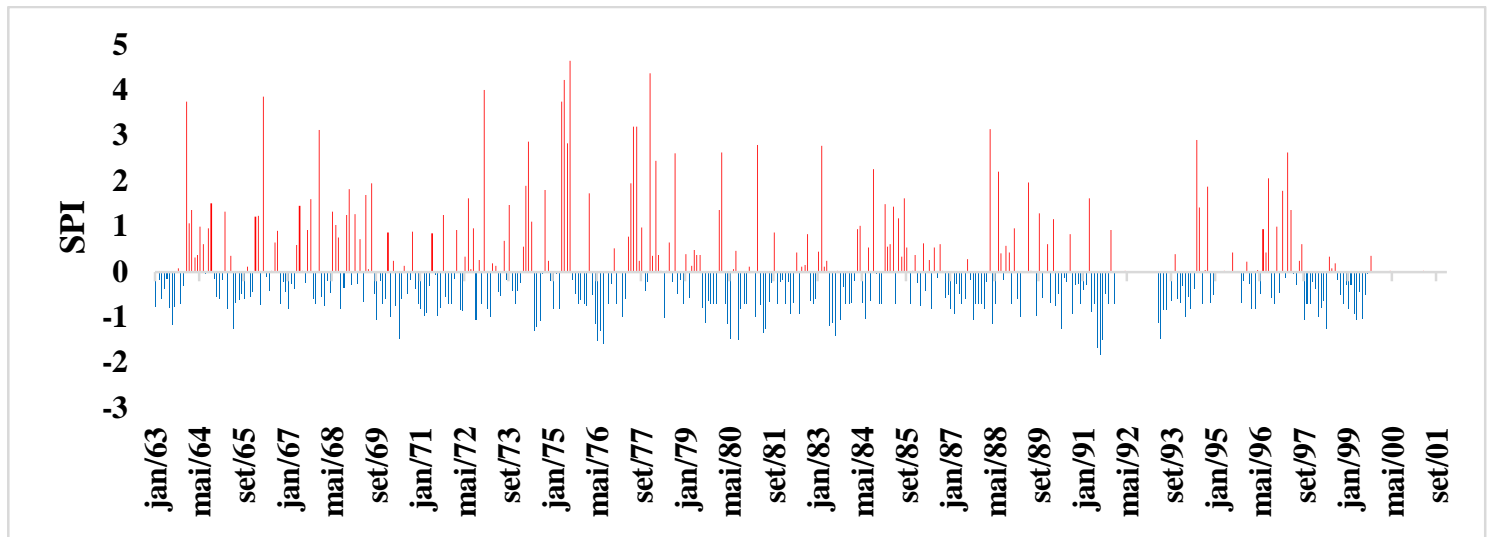

Fonte: Autores (2018).

Em Santana do Ipanema (Figuras 11 e 12) $40 \%$ dos casos classificaram-se como quase normal, e $36 \%$ como de seca, sendo seca leve em maior número, com $25 \%$, com o mais forte evento de seca extrema acontecendo em junho de 1974. Já a quantidade de chuvas acima da média foi de $24 \%$, com atenção para os meses de julho, abril, setembro, maio, novembro e agosto do ano de 1963.

Em Traipu (Figuras 13 e 14) 44\% dos eventos foram normais, $35 \%$ foram secas, e já a chuva registrada acima da média ficou na porcentagem de $21 \%$. Dentre os eventos de seca, o mais frequente foi a seca leve com $26 \%$, e a maior seca registrada foi em maio de 1970. A maior chuva extrema registrada foi em Dezembro de 1963, ano em que ocorreu um El niño fraco. 
Figura 11 - Número de casos de chuva/seca em Santana do Ipanema (Sertão)

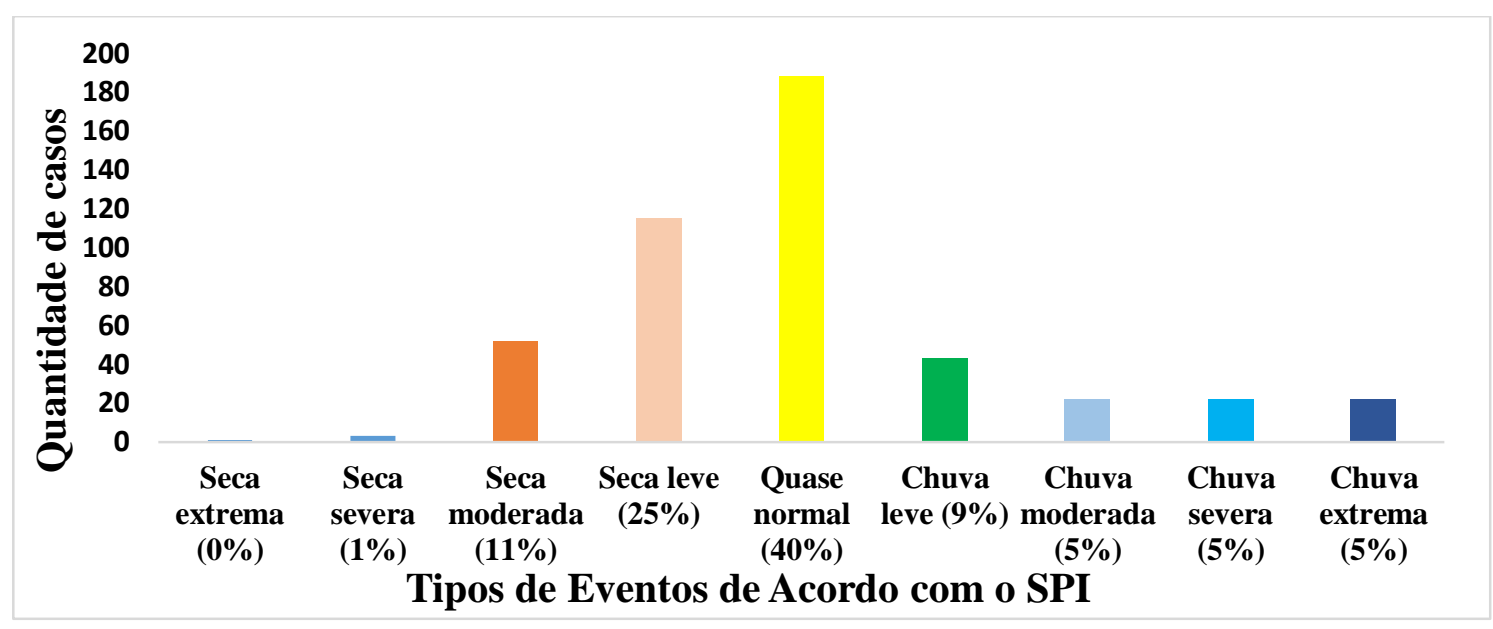

Fonte: Autores (2018).

Figura 12 - Série de SPI para Santana do Ipanema (Sertão)

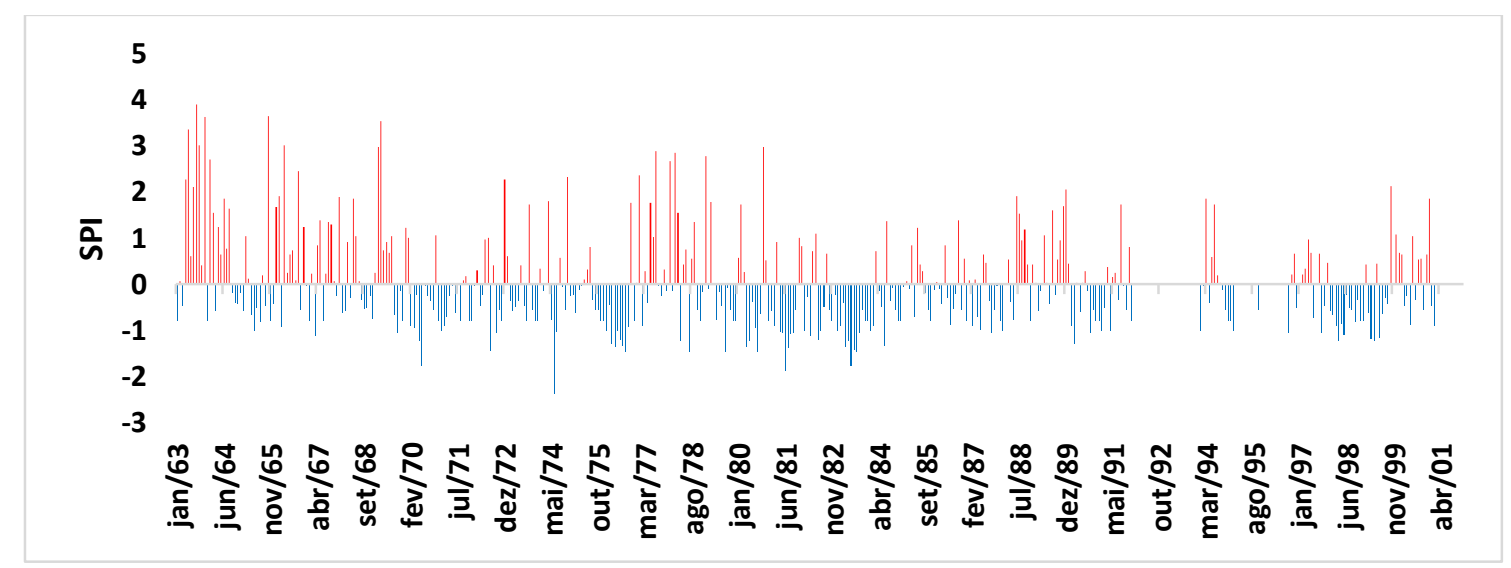

Fonte: Autores (2018). 
Classificação, quantificação e ocorrência de eventos climáticos extremos nas três mesorregiões do estado de Alagoas, Brasil

Figura 13 - Número de casos de chuva/seca em Traipu (Agreste)

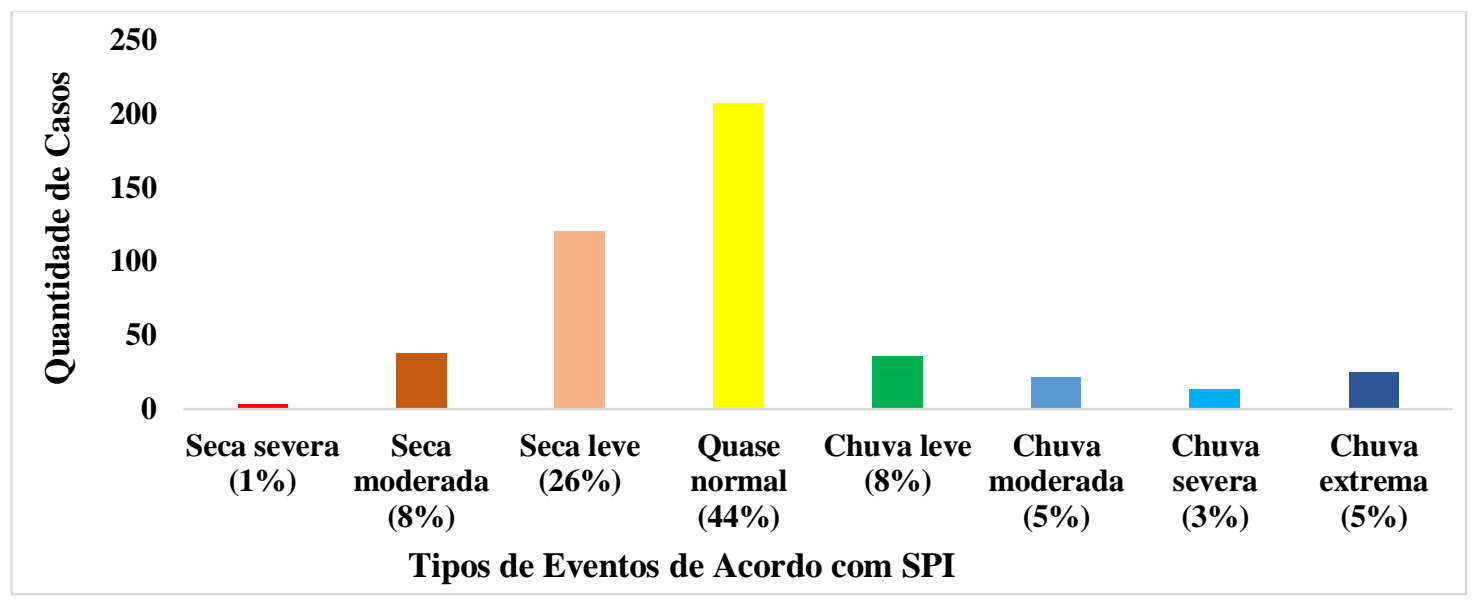

Fonte: Autores (2018).

Figura 14 - Série de SPI para Traipu (Agreste)

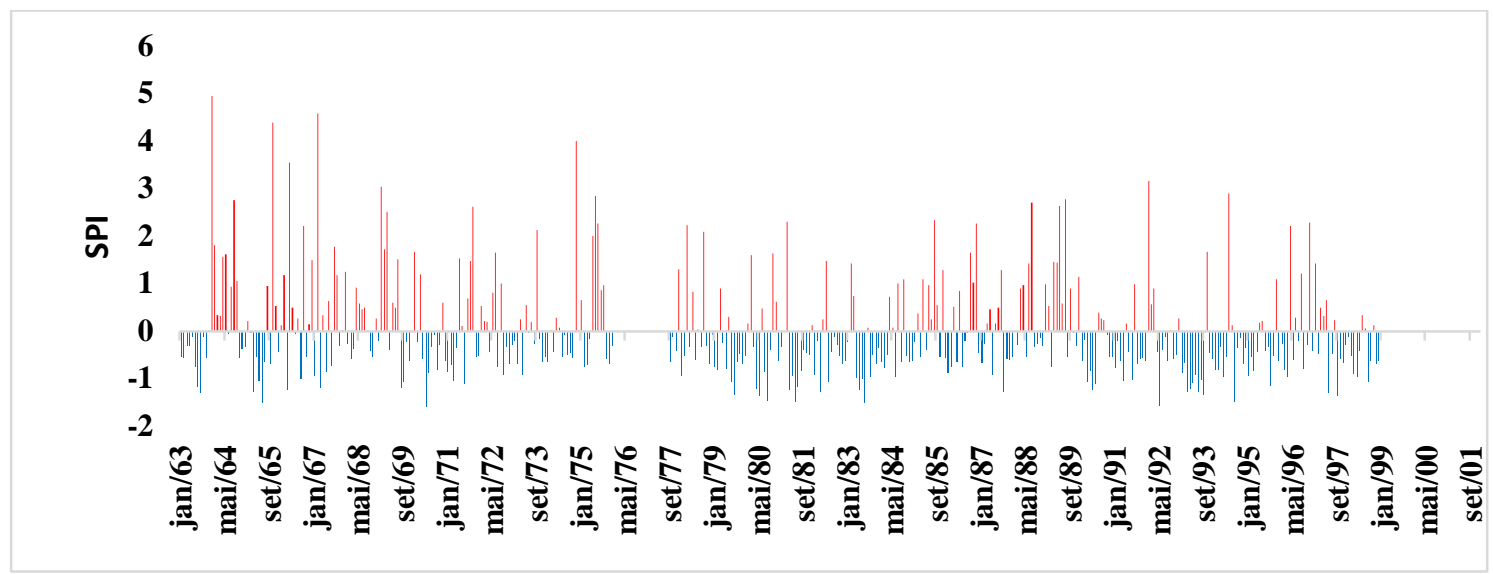

Fonte: Autores (2018).

$\mathrm{Na}$ cidade de Piaçabuçu (Figuras 15 e 16) $43 \%$ dos casos foram classificados como quase normal, houve ocorrência de $32 \%$ de secas, sendo a mais severa registrada em julho de 1973, ano em que houve registro de forte El niño. Já com relação à chuva, houve $25 \%$ de ocorrência de chuvas acima do normal, e a mais extrema foi em julho de 1975, ano em que teve um forte La Niña (CPTEC, 2018). 
Figura 15 - Número de casos de chuva/seca em Piaçabuçu (Zona da Mata)

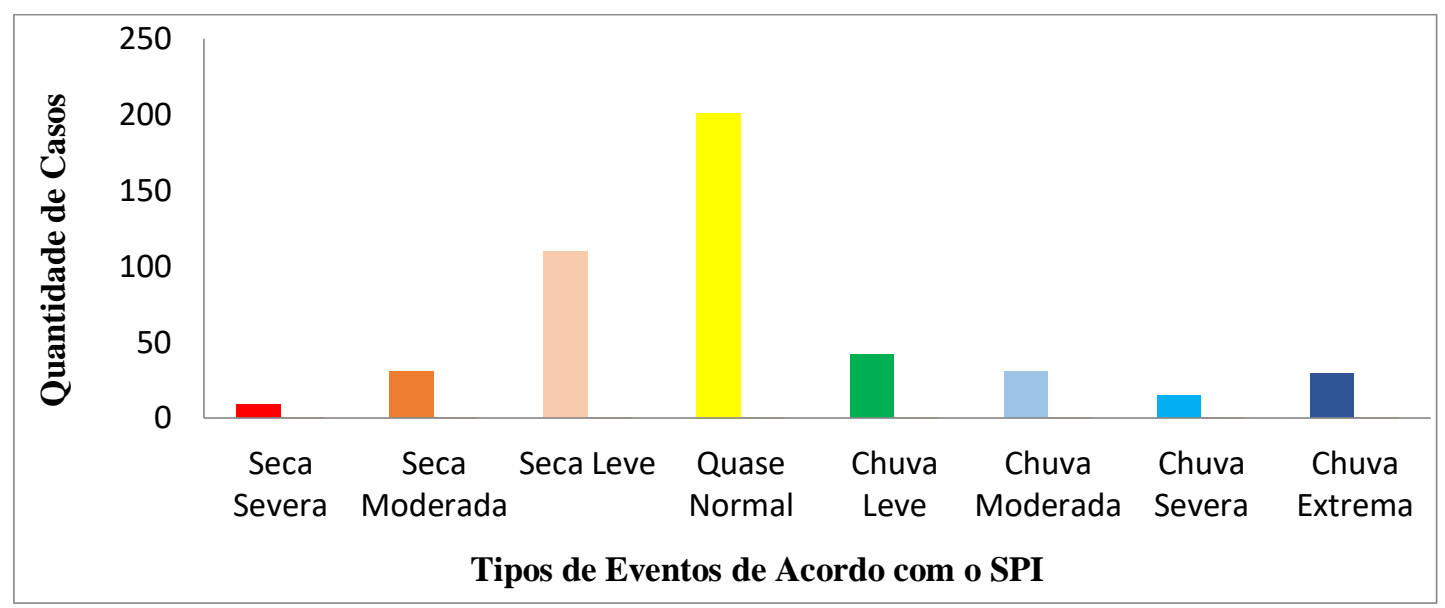

Fonte: Autores (2018).

Figura 16 - Série de SPI para Piaçabuçu (Zona da Mata)

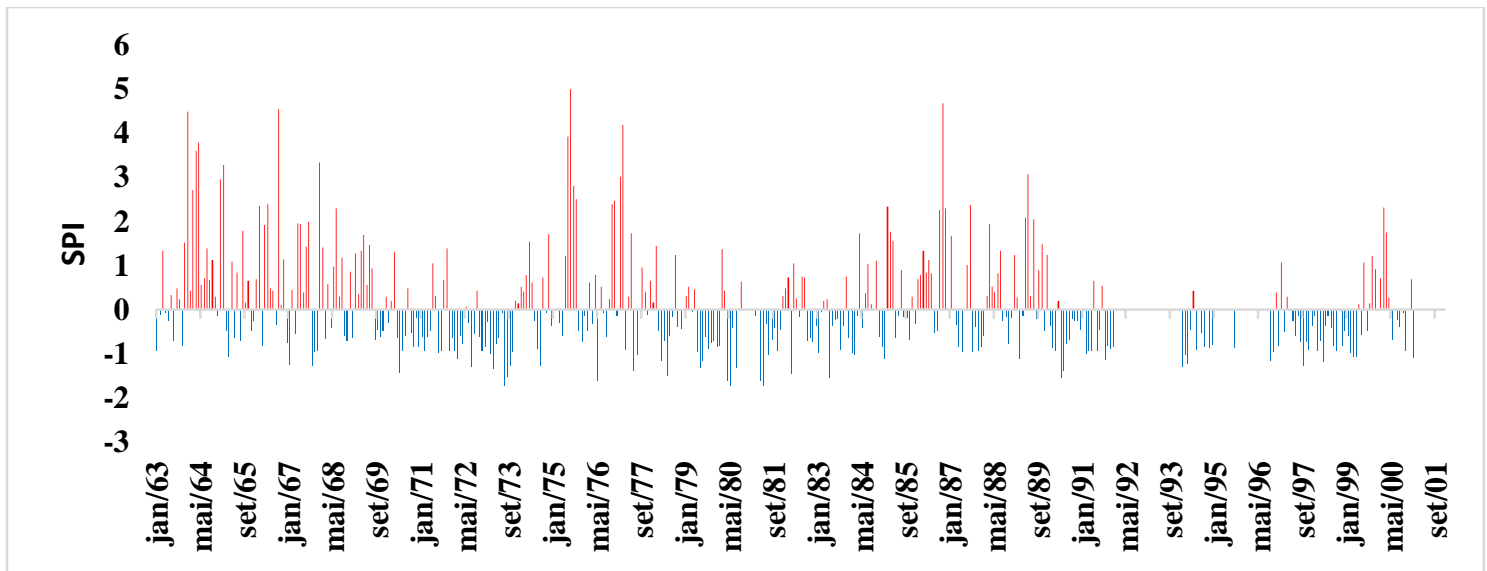

Fonte: Autores (2018).

$\mathrm{Na}$ análise de distribuição de eventos conforme o SPI para Igreja Nova (Figuras 17 e 18) quantificou-se 6 ocorrências de seca severa, 48 de seca moderada e 102 de seca leve; totalizando 185 ocorrências, o que representa $34,11 \%$ dos eventos. Já na distribuição de eventos de chuvas registrou-se 52 ocorrências de chuva leve, 25 de chuva moderada, 17 de chuva severa e 21 de chuva extrema; tendo como resultado um total de 115 casos de eventos de chuvas, totalizando $25,22 \%$. Os casos de eventos de chuva extrema (valores do SPI > 2) correspondem a $4,61 \%$ do total, e já os extremos de seca não ocorrerão. 
Classificação, quantificação e ocorrência de eventos climáticos extremos nas três mesorregiões do estado de Alagoas, Brasil

Os resultados encontrados aqui corroboram com os de Nascimento et al. (2017), que ao usar o SPI para o Maranhão, notou que a maioria dos casos de eventos extremos tanto secos quanto chuvosos, ocorreram em anos de ENOS. Os eventos de chuva extrema foram mais intensos.

Analisando a distribuição dos eventos classificados por SPI para a cidade de Murici (Figuras 18 e 19) foi possível quantificar 16 casos para chuvas severas, 26 para chuvas moderadas, 27 para chuvas consideradas leves e 21 ocorrências para chuvas extremas, registrada em dezembro de 1989, ano de ocorrência de El niño moderado. Já para seca considerada leve foi apresentada 62 ocorrências e 63 para seca moderada, totalizando $27,41 \%$ dos casos.

Figura 17 - Número de casos de chuva/seca em Igreja Nova (Zona da Mata)

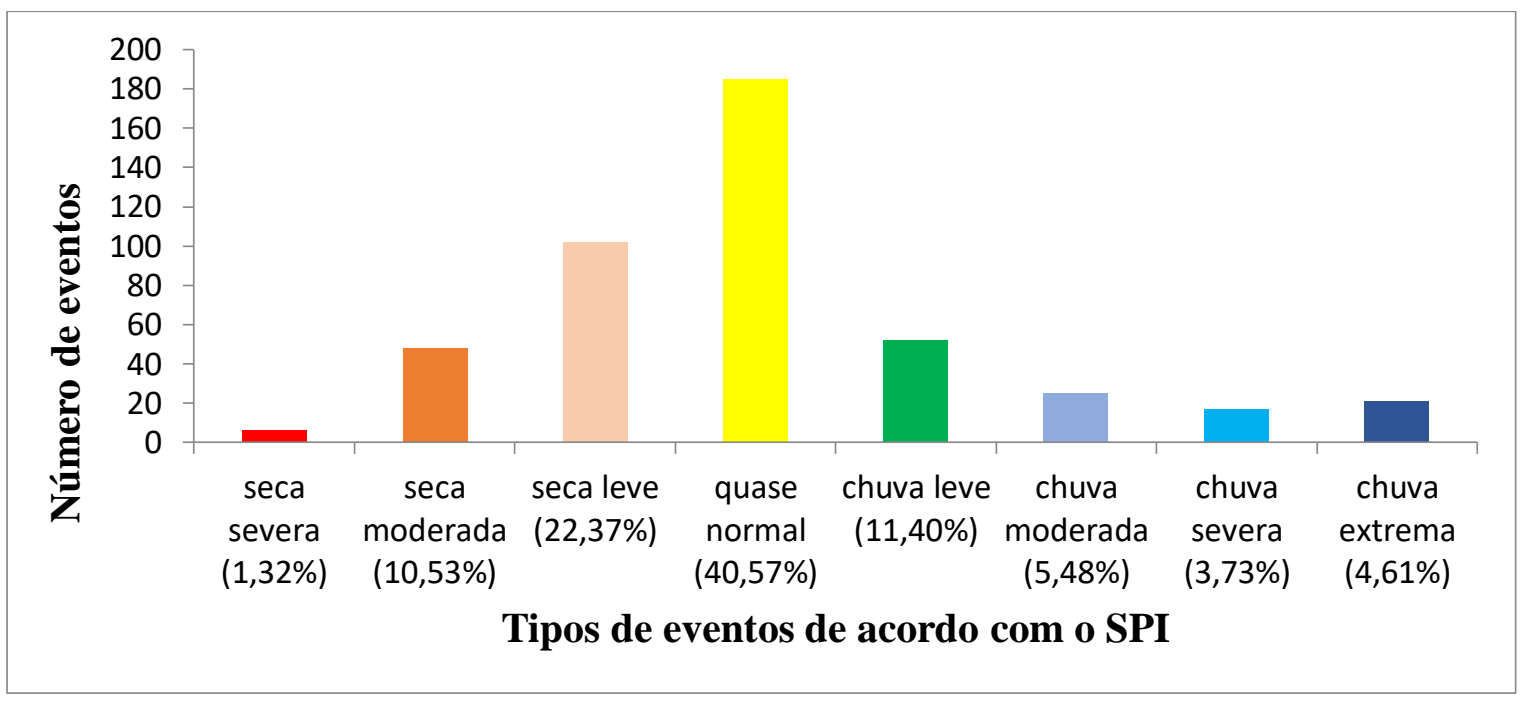

Fonte: Autores (2018). 
Figura 18 - Série de SPI para Igreja Nova (Zona da Mata)

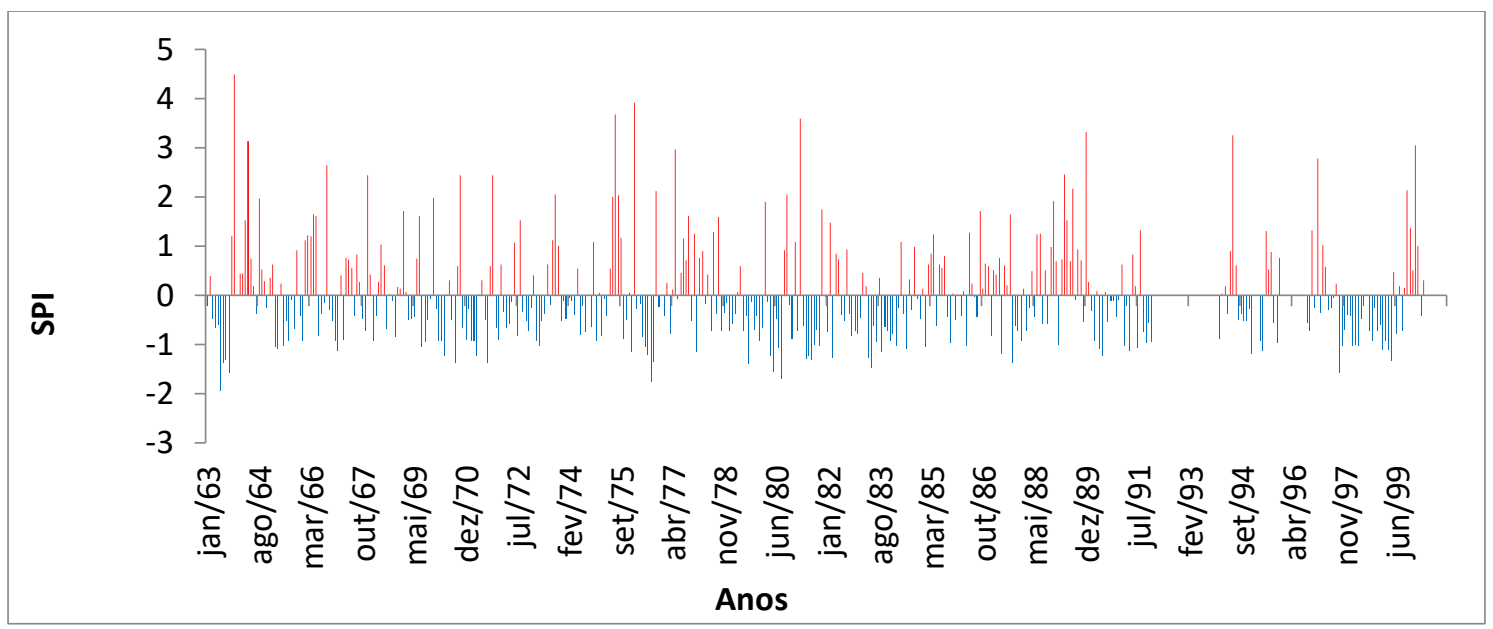

Fonte: Autores (2018).

Figura 19 - Número de casos de chuva/seca em Murici (Zona da Mata)

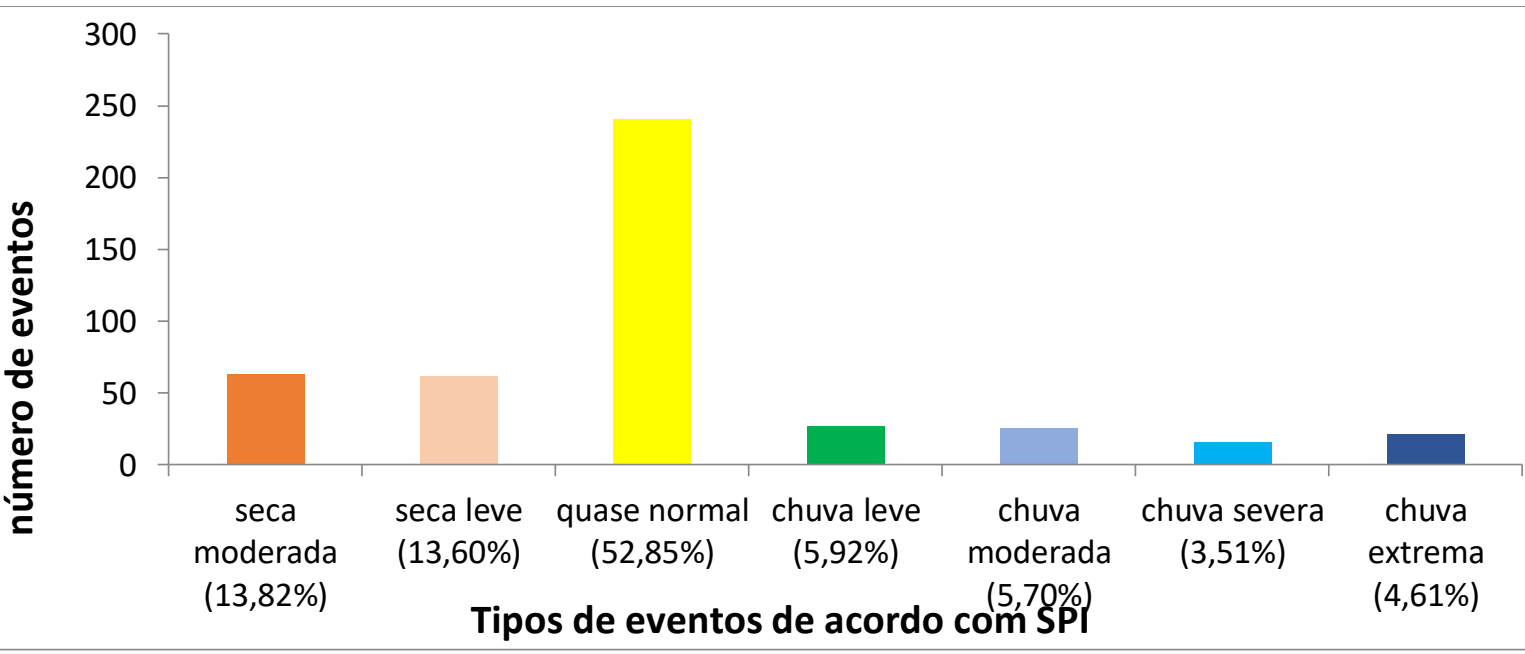

Fonte: Autores (2018). 
Figura 20 - Série de SPI para Murici (Zona da Mata)

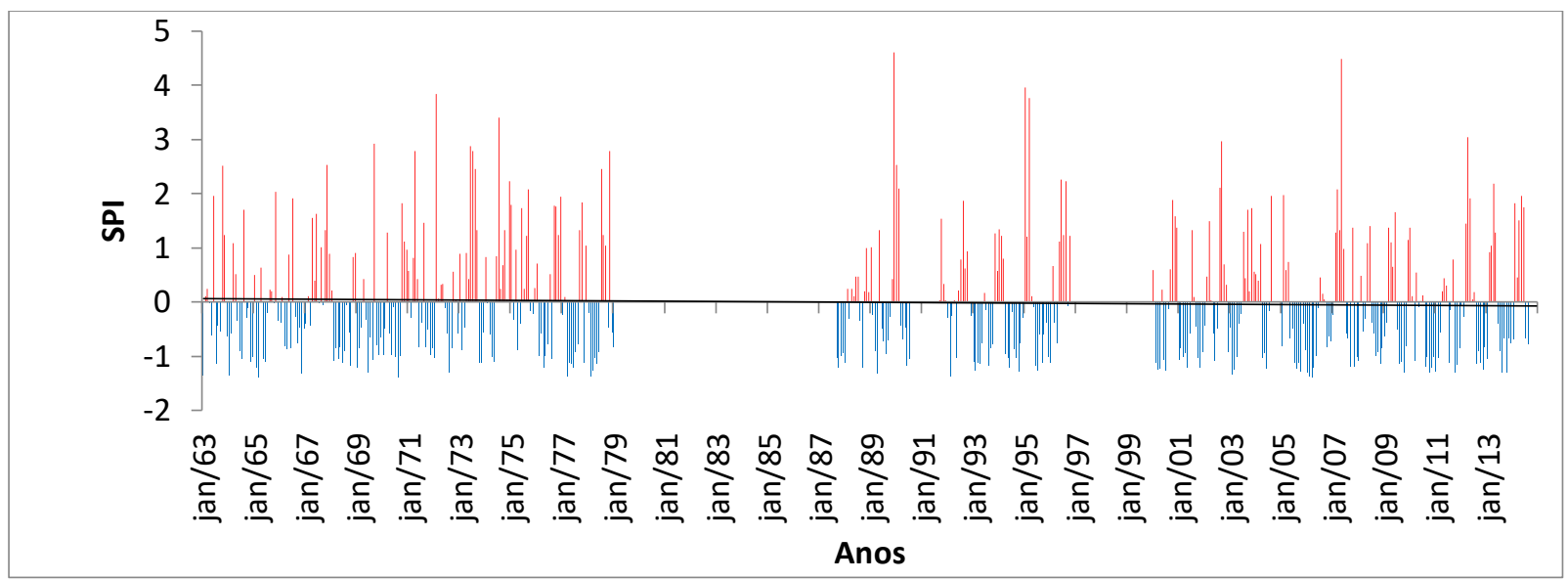

Fonte: Autores (2018).

Através da análise da série temporal de SPI para Flexeiras (Figuras 21 e 22) é possível identificar os anos secos e chuvosos. 0 principal destaque de ocorrência de seca extrema, com forte pico negativo, ocorreu nos anos de 1970, 1995, 1996 e 2001, quando a intensidade ficou abaixo de -2,00 (1970 e 1995), anos estes associados à ocorrência do fenômeno El Nino, de moderada intensidade. Tal atuação pode ter influenciado e intensificado os eventos secos.

Outra seca destacada foi a de intensidade severa, que ocorreu nos anos de 1966, 1970, 1995, 1996, 1999 e 2001 (Figuras 21 e 22), com intensidade abaixo de 1,99 a -1,50. Nos anos de 1966, 1970 e 1995, também houve ocorrência do El Nino moderado, podendo ter influenciado os eventos de seca.

Conforme também identificado por Macedo et al. (2010) em estudos na cidade de Coremas, Estado da Paraíba, que observaram que a seca severa no ano de 1995 estava relacionada com o El Nino moderado.

Com intensidade abaixo de -1,49 a -1,0 ocorreram secas moderadas nos anos de 1963 a 1965, 1966 a 1973, 1975 a 1981, 1983 a 1990, 1995 a 2001. Ocorreu El Nino moderado nos anos de 1963, 1966, 1970, 1971, 1987 e 1995, e El Nino forte nos anos de 1972, 1973, 1983, 1990 e 1998 que pode ter relacionado com os eventos de seca na região.

As chuvas extremas ocorrem nos anos de 1963, 1965, 1972, 1975 a 1978, 1980, 1981, 1985, 1986, 1988, 1989, 1991, 1994, 1996 e 2000, com intensidade acima de 2,00. Essas ocorrências podem ter sido, possivelmente, devido à atuação do 
fenômeno La Nina que ocorreu nos anos de 1965, 1985 e 1996 (CPTEC, 2018). Com intensidade acima de 1,00 tem-se as chuvas severas e moderadas, a maior intensidade ocorre nos anos de 1963, 1969, 1970, 1973, 1975, 1978, 1979, 1980, 1982, 1984, 1985 a 19871991 e 1994. Ouve ocorrência de La Niña nos anos 1984 e 1985, que pode ter influenciado nas chuvas severas e moderadas desses anos.

Na distribuição de frequência do SPI para a cidade de Flexeiras, registrou 7 ocorrências de seca extrema, 13 de seca severa, 55 de seca moderada e 117 de seca leve; totalizando 192 eventos, que corresponde a 46,24\% dos eventos. Quase normal registrou 152 que corresponde a 34,23 dos eventos. Na distribuição de eventos de chuvas foram notados 43 episódios de chuva leve, 18 de chuva moderada, 15 de chuva severa e 24 de chuva extrema; totalizando 100 ocorrências que corresponde a $22,52 \%$ dos eventos.

Figura 21 - Número de casos de chuva/seca em Flexeiras (Zona da Mata)

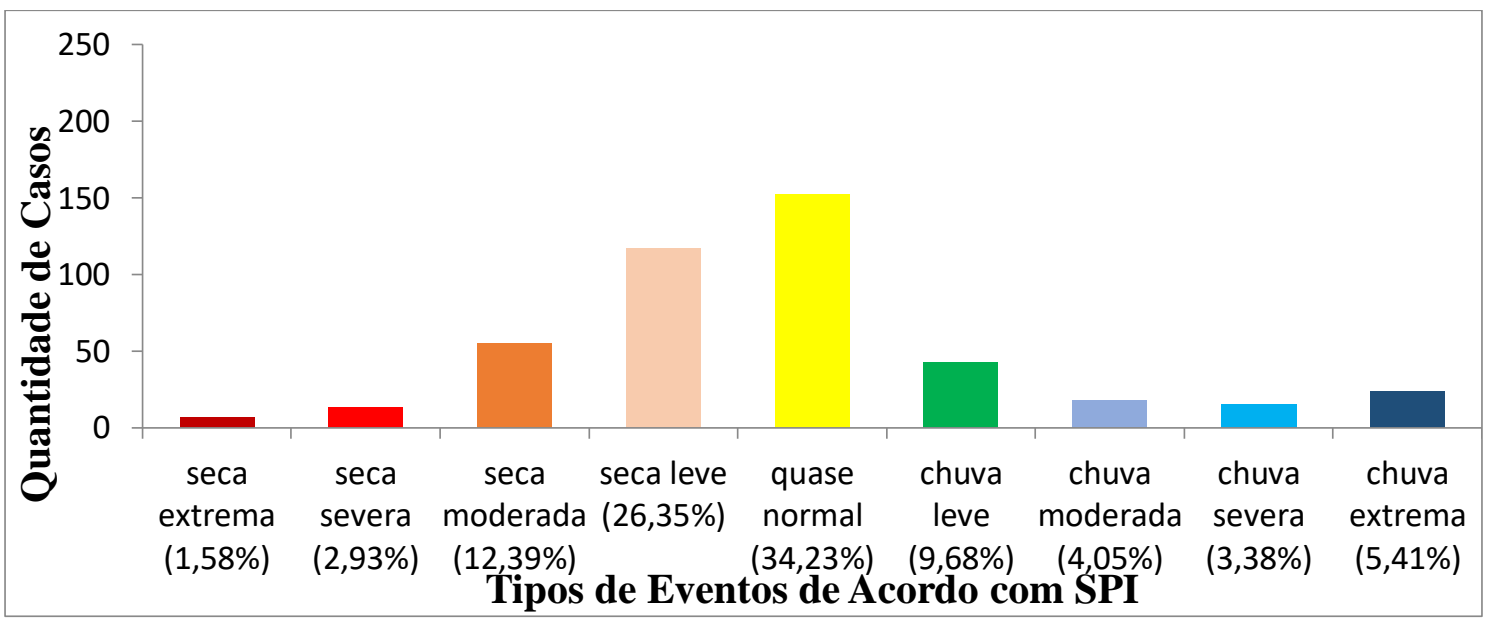

Fonte: Autores (2018). 
Figura 22 - Série de SPI para Flexeira (Zona da Mata)

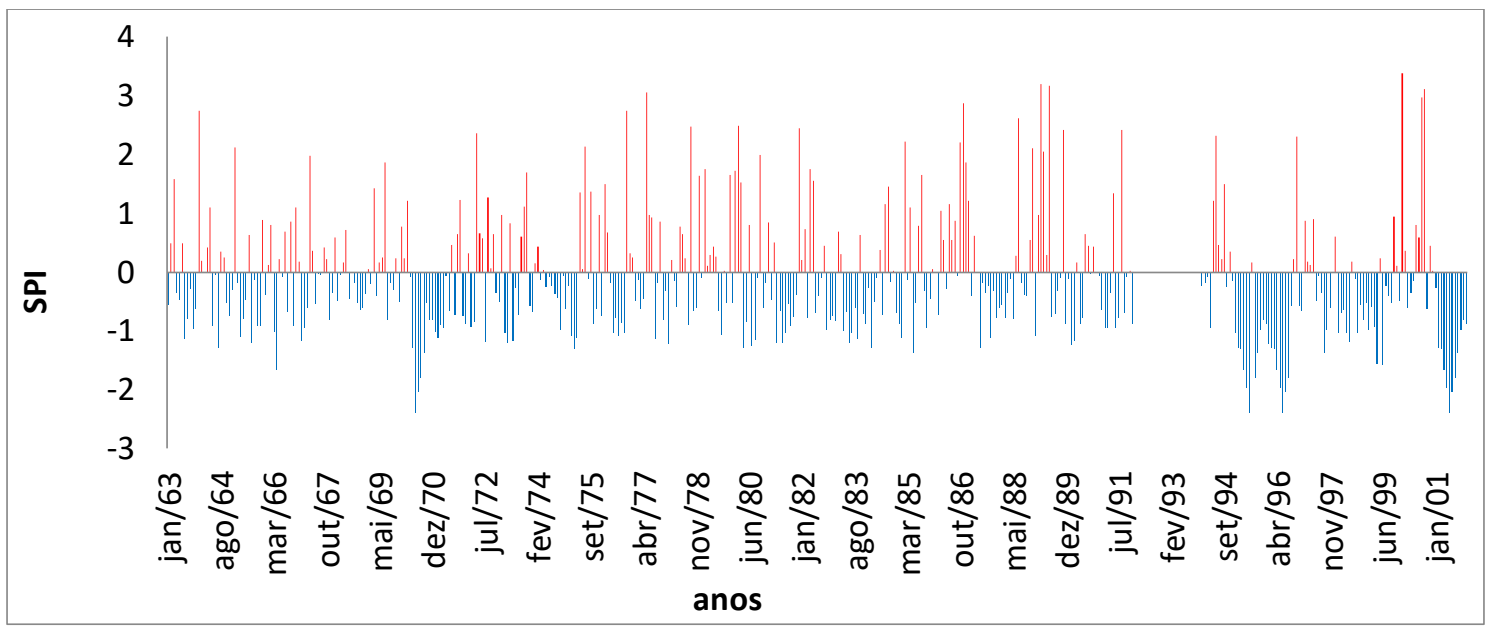

Fonte: Autores (2018).

\section{CONSIDERAÇÕES FINAIS}

Observou-se em todas as cidades estudadas que o maior percentual sempre foi de ocorrência de eventos normais, e pode-se afirmar que as quantidades de ocorrência de secas são sempre maiores que a ocorrência de chuvas acima da média, tendo como exemplo as cidades de Piranhas e Traipu, respectivamente regiões Sertão e Agreste. Já as cidades de Piaçabuçu (Zona da Mata) e a Santana do Ipanema (Sertão) foram as que apresentaram maior quantidade de chuvas acima da média.

As cidades de Batalha e Delmiro Golveia (ambas da região Sertão), ambas com $58 \%$ de casos normais, foram as que apresentaram menor variação, mostrando assim menores variações nos períodos de secas e de chuvas acima da média.

Em Igreja Nova, assim como na cidade de Murici, ambas da Zona da Mata, apresentaram maiores ocorrências de eventos de seca de acordo com os dados, se comparados com os totais pluviométricos.

$\mathrm{Na}$ cidade de Flexeiras (Zona da Mata), baixos valores de precipitação acumulada ocorreram devido à ocorrência do evento El Niño moderado.

De modo geral, os eventos secos mostraram maior percentual de ocorrência, porém de baixa intensidade, associados a anos de El Niño; e menores percentuais de chuvas com maiores intensidades, associados a La Niña. Desta forma, a inovação 
deste trabalho desmistificada a imagem que se tem do Nordeste do Brasil; que todas as secas são sempre de maior intensidade, e sempre causadas pelo El Niño.

Por fim, o SPI revelou-se uma ferramenta útil e eficiente para detecção e monitoramento de seca/chuvas no Estado de Alagoas.

\section{REFERÊNCIAS}

BONFIM, O. E. T.; DA SILVA, D. F. Influência do ENOS canônico e modoki sobre a ocorrência de eventos extremos na bacia hidrográfica Aguapeí-Peixe (SP). Revista Ibero-Americana de Ciências Ambientais, v. 9 n. 3, 2018.

CPTEC - Centro de Previsão de Tempo e Estudos Climáticos -. La Niña. El Niño.Instituto Nacional de Pesquisas Espaciais. 2018. Disponível em: http://enos.cptec.inpe.br/ Acesso em 25/10/2018.

CPTEC - Centro de Previsão de Tempo e Estudos Climáticos. Instituto Nacional de Pesquisas Espaciais. Índice de precipitação padronizado (SPI). 2018. Disponível em: http://clima1.cptec.inpe.br/spi/pt. Acesso em: 21 de agosto de 2018.

DA SILVA, D. F. Previsão Hidro-climática para prevenção de desastres naturais do leste do Nordeste do Brasil utilizando análises estatísticas avançadas. Projeto Edital Universal - CNPq, p. 4-21, 2014.

FERNANDES, D. S. et. al. Índices para a Quantificação da Seca. Santo Antônio de Goiás: Embrapa Arroz e Feijão, 2009. 48 p. (Embrapa Arroz e Feijão. Documentos, 244).

GUEDES, R.V. S.; et. al. Análise espacial de eventos de secas com base no índice padronizado de precipitação e análise de agrupamento. Revista Brasileira de Ciências Ambientais, v. 1, n. 23, p. 55-65, 2012.

HAYES, M. J.; et al. Monitoring the 1996 drought using the Standardized Precipitation Index. Bulletin of the American Meteorological Society, v. 80, n. 3, p. 429-438, 1999.

MACEDO, M. J. H.; et al. Análise do índice padronizado de precipitação para o estado da Paraíba, Brasil. Ambi-Agua, Taubaté, v. 5, n. 1, p. 204-214, 2010.

MCKEE, T. B. et. al. The relationship of drought frequency and duration of time scales. Eighth Conference on Applied Climatology, American Meteorological Society, Jan17-23, 1993, Anaheim CA, pp.179-186. 
MOLION, L. C. B.; BERNARDO, S. O. Uma revisão da dinâmica das chuvas no Nordeste Brasileiro. Revista Brasileira de Meteorologia, v.17, n.1, p. 1-10, 2002.

SANTOS, S.R.Q.; et. al. Determinação de Regiões Homogêneas do Índice de Precipitação Normalizada (SPI) na Amazônia Oriental. Revista Brasileira de Meteorologia, v. 32, n. 1, p. 111-122, 2017.

SOUSA, F. A. S.; MACEDO, M. J. H.; GUEDES, R.V. S.; SILVA, V. P. R. O Índice de Precipitação Padronizada (IPP) na identificação de extremos de chuvas e secas na bacia do rio Paraguaçu (BA). Revista Ambiência, Guarapuava, v. 12, n. 2, p. 707-719, 2015.

SUPORTE GEOGRÁFICO. Clima de alagoas. 2018. Disponível em:

https://www.infoescola.com/geografia/clima-de-alagoas/. Acesso em: 27 de ago. de 2018.

TEIXEIRA, C. F. A.; DAMÉ, R. C. F.; BACELAR, L. C. S.; SILVA, G. M.; COUTO, R. S. Intensidade da seca utilizando índices de precipitação. Ambi-Agua, Taubaté, v. 8, n. 3, p. 203-213, 2013.

ULIANA, E. M.; DOS REIS, E. F.; DE SOUZA, A. P.; DA SILVA, J. G. F.; XAVIER, A. C. Utilização do Índice de Precipitação Padronizado para a Região Norte do Estado do Espírito Santo. Revista Irriga, Botucatu, v. 20, n. 3, p. 414-428, 2015. 